\title{
Design and experimental study of seed precise delivery mechanism for high-speed maize planter
}

\author{
Quanwei Liu ${ }^{1,2}$, Tao Cui ${ }^{1}$, Dongxing Zhang ${ }^{1}$, Li Yang ${ }^{1 *}$, Yunxia Wang ${ }^{1}$, Xiantao He ${ }^{1}$, Mantao Wang ${ }^{1}$ \\ (1. College of Engineering, China Agricultural University, Beijing 100083, China; \\ 2. School of Mechatronics Engineering, Zhengzhou University of Aeronautics, Zhengzhou 450046, China)
}

\begin{abstract}
Aiming at improving the seed spacing uniformity of maize planter at high forward speed, a seed precise delivery mechanism driven by electric motor has been developed and evaluated in laboratory. The mechanism was designed to deliver single seed from seed meter to furrow. Seed's movement from the seed release point in a seed meter to the seed delivery cavity in the belt was analyzed, the mathematical model of seed movement in the seed precise delivery mechanism was established based on seed delivery time analysis. A mechanical prototype was designed and associated control system was developed. The performance contrast experiment was conducted between a traditional seed tube and newly developed seed precise delivery mechanism, and test results indicated that the qualities of feed index of the seed precise delivery mechanism were higher than those of the traditional seed tube delivery mechanism, and the coefficients of variation of the seed precise delivery mechanism were lower than those of the traditional seed tube delivery mechanism when the forward speed of planter was set at $10 \mathrm{~km} / \mathrm{h}, 12 \mathrm{~km} / \mathrm{h}$ and $14 \mathrm{~km} / \mathrm{h}$, respectively. It indicated the seed precise delivery mechanism significantly improved seed spacing uniformity of maize planter compared with the traditional seed tube delivery mechanism.
\end{abstract}

Keywords: seed precise delivery mechanism, electric motor, seed spacing uniformity, delivery time, mechanical prototype DOI: $10.25165 /$ j.ijabe.20181104.2802

Citation: Liu Q W, Cui T, Zhang D X, Yang L, Wang Y X, He X T, et al. Design and experimental study of seed precise delivery mechanism for high-speed maize planter. Int J Agric \& Biol Eng, 2018; 11(4): 81-87.

\section{Introduction}

Precision sowing is the preferred method among different sowing techniques, since it provides more uniform seed spacing compared with other methods. Singh et al. ${ }^{[1]}$ provided a definition of precision planting, which is placement of single seed into the soil at the desired plant spacing. The distribution of spacing between plants in a soil bin or in the field has been used as a performance parameter ${ }^{[2-6]}$. The sowing devices equipped with single seed metering devices are called precision planters. High speed and high efficient precision planting technology is becoming more widespread in maize planting because of the advantages of seed-saving, avoiding seedling thinning, keeping seed spacing uniformity both in longitudinal distribution and in depth, and increasing crop yield ${ }^{[7]}$. The main objective of precision sowing was to ensure that the seeds are put at a desired inter-row spacing and depth, which resulted in higher emergence rate and increased crop yield by decreasing competition between plants for available light, water, and nutrients ${ }^{[8]}$.

Received date: 2016-11-23 Accepted date: 2017-12-01

Biographies: Quanwei Liu, PhD, research interests: corn precision planter and its control system. Email: liuquanwei@cau.edu.cn; Tao Cui: PhD, research interests: corn planting and harvesting technology, Email: cuitao850919@163.com; Dongxing Zhang: Professor, research interests: corn planting and harvesting technology, Email: zhangdx@cau.edu.cn; Yunxia Wang: $\mathrm{PhD}$ candidate, research interests: corn precision planter. Email: wangyxsdau@126.com; Xiantao He: PhD candidate, research interests: corn precision planter and its control system, Email: hxt@cau.edu.cn; Mantao Wang, Master, research interests: corn precision planter and its control system, Email: wangmtgs@163.com. *Corresponding author: Li Yang, PhD, Professor, research interests: modern agricultural machinery and planting technology. Mailing address: College of Engineering, China Agricultural University, Beijing 100083, China. Email: yangli@cau.edu.cn.
Seed spacing uniformity in the field is mainly influenced by precision seed-metering system, which is the core part of a precision planter. The precision seed meter is used to separate seed from seed group, forming uniform and orderly seed flow, the seed guide device mounted below the outlet of the seed meter is used to guide seeds to drop from a seed meter into the furrow opened in the ground. Some high-performance seed meters have been developed, such as the vSet meter developed by Precision Planting Corporation in the USA produced superior results with the quality of feed index of $99.06 \%$ at the speed of $12 \mathrm{~km} / \mathrm{h}$ in the meter testing by a bench experiment. A pneumatic maize precision seed meter with combined seed holes developed by Shi et al. ${ }^{[9]}$ reached the quality of feed index up to $98.60 \%$ at the speed of $12 \mathrm{~km} / \mathrm{h}$ in seed meter testing. Seed drill performance with regard to seed spacing was measured using different methods ${ }^{[10-15]}$. Erbach et al. ${ }^{[16]}$ conducted a contrast experiment of seed spacing uniformity between a planter equipped with a V-type double-disk furrow openers with and without a seed tube and his conclusion was drawn that the standard deviation of plant spacing without the seed tube was $6.0 \mathrm{~cm}$, which was significantly greater than with the seed tube $(4.4 \mathrm{~cm})$. Moody et al. ${ }^{[17]}$ stated that spacing variability was mainly caused by the metering unit, and/or bounce of the seed in the top half of the seed tube. Sowing performance is mainly affected by the performance of seed meter and the design structure of seed guide device, such as shape of seed guide device, tilt angle, sectional area, length and smoothness. Seed guide device in common use are divided into such two types as seed tube and inverted parabolic curve seed guide device ${ }^{[18]}$. A seed tube was designed and manufactured by Liu and Yang $^{[19]}$ based on 3D reverse engineering design, and test result indicated that it can improve sowing quality effectively. Mathematical modeling of seed tube was made based on mechanical analysis, and the curve of seed tube was obtained by computer programming ${ }^{[20]}$. 
Mathematical modeling of seed tube was built and kinematics of seed tube was analyzed, curve equation and optimal value were obtained finally ${ }^{[21]}$.

When rotational speed of seed plate was less than $30 \mathrm{r} / \mathrm{min}$, most seeds were discharged along the wall of seed guide device, and the seed spacing uniformity met the requirement of precision sowing. When rotational speed of seed plate was more than $30 \mathrm{r} / \mathrm{min}$, the collision and bounce of seeds in seed tube aggravated as mechanical vibration intensified, thus difficult to obtain accurate delivery into the furrow at high operating speed of maize planter ${ }^{[22-24]}$

The aim of this study was to design and develop a new seed precise delivery mechanism driven by motor, which can effectively decrease the variability of seed spacing in soil and improve the quality of feed index of high-speed planter. Mechanical prototype was designed and associated control system was developed. A performance contrast experiment was conducted between a traditional seed tube delivery and a newly developed seed precise delivery mechanism.

\section{Materials and methods}

\subsection{Structure and working principle of seed precise delivery mechanism}

In order to improve seed spacing uniformity at high forward speed of maize planter, a motor-driving seed precise delivery mechanism was developed. As shown in Figure 1, the system consists of a motor-driving air-suction seed meter, a motor-driving belt type seed delivery device and a control system. The system works this way: the negative-pressure fan began to work to create a vacuum in air chamber in the seed meter after the system switch was turned on, then the seed-prefilling switch was turned on, the belt with partition board moved, driven by the meter-driving motor. When the partition board arrived at the installation position of U-shaped electro-optical sensor, pulley-driving step motor stopped, and the feed shaft-driving step motor started to work, one or more seeds were attached on a seed hole of seed plate under the pressure difference and moved with the seed plate. Extra seeds were eliminated when the seed hole with seeds passed the seed eliminator located in the upper-left of the seed meter. One seed was left on the seed hole and it entered seed-falling zone with the rotation of the seed plate. When the first seed dropped from seed plate and passed the installation position of diffuse electro-optical sensor, the synchronous belt with partition board began to move, the seed dropped to a seed delivery cavity and moved with the synchronous belt with partition. When the pulley-driving motor rotated for certain revolutions, the first seed was delivered to the bottom of the belt-type seed delivery device. When the sowing operation was ready to begin, double-motor synchronizing drive switch was turned on, the forward speed of maize planter was detected by the encoder mounted on the land wheel, then appropriate rotation speeds of the two motors were determined to match the forward speed of maize planter, the two motors rotated in synchronization, and seeds dropped to the furrow when the mechanism worked.

\subsection{Design of motor driven seed precise delivery mechanism}

\subsubsection{Kinematic analysis of maize seed}

As shown in Figure 2, when arriving at the seed-release point with the seed plate rotating, the seed dropped from the seed plate and entered the corresponding seed-delivery cavity under the pushing force from seed pushing board and the seed's own weight.
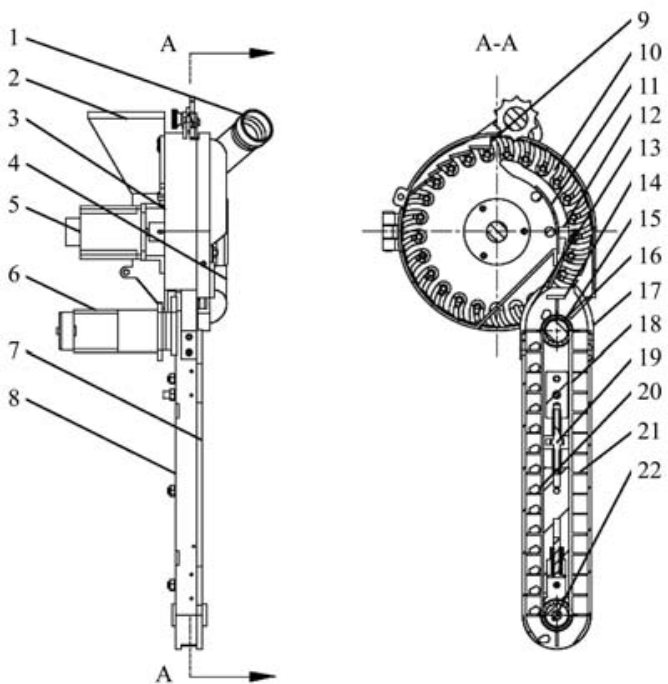

1. Air suction pipe 2. Seed inlet 3. Front case of seed meter 4. Rear case of seed meter 5. Feed shaft-driving motor 6. Pulley-driving motor 7. Front case of seed delivery device 8 . Rear case of seed delivery device 9. Seed eliminator 10. Seed plate 11. Seed-pushing board 12. Seed-guiding board 13. Left seed-protecting board 14. Diffuse electro-optical sensor 15. Driving pulley 16. U-shaped electro-optical sensor 17. Right seed-protecting board 18. Synchronous belt with partition board 19. Double-headed stud 20. Seed 21. Partition board 22. Driven pulley

Figure 1 Structure diagram of seed precise delivery mechanism

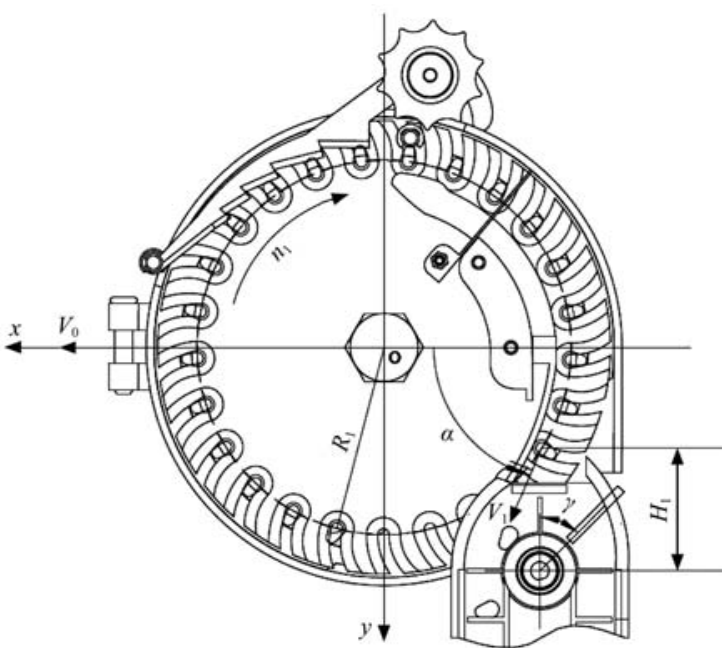

Note: $O$ is the origin of coordinate; $x$-axis is the horizontal axis; $y$-axis is the vertical axis; $V_{0}$ is the forward speed of maize planter, $\mathrm{km} / \mathrm{h} ; V_{1}$ is the seed falling velocity from seed-release point, $\mathrm{m} / \mathrm{s} ; n_{1}$ is the rotational speed of seed plate, $\mathrm{r} / \mathrm{min} ; R_{1}$ is the distribution radius of seed hole in seed plate, $\mathrm{m} ; \alpha$ is the seed release angle, $\left(^{\circ}\right) ; \gamma$ is the angle between the mounting position of electro-optical sensor and the vertical direction, $\left(^{\circ}\right) ; H_{1}$ is the vertical distance between the seed release point and the central point of driving pulley, $\mathrm{m}$.

Figure 2 Schematic drawing of seed motion analysis

The velocity and displacement of seed from the seed-release point to the seed-delivery cavity were calculated by using the following formulas:

$$
\begin{aligned}
& \left\{\begin{array}{l}
\frac{d X}{d t}=V_{1} \cos \alpha \\
\frac{d Y}{d t}=V_{1} \sin \alpha
\end{array}\right. \\
& \left\{\begin{array}{l}
X=\frac{d X}{d t} t \\
Y=\frac{d Y}{d t} t+\frac{1}{2} g t^{2}
\end{array}\right.
\end{aligned}
$$

where, $X$ is the seed's displacement in the $X$ direction, $\mathrm{m}$; $Y$ is the 
seed's displacement in the $Y$ direction, $\mathrm{m}$; $t$ is the time that the seed takes to fall, $\mathrm{s} ; V_{1}$ is the seed falling velocity from seed-release point, $\mathrm{m} / \mathrm{s} ; \alpha$ is the seed release angle, $\left({ }^{\circ}\right)$.

From Equations (1) and (2), the displacements of seed in the horizontal direction and vertical direction were calculated by using the following formulas:

$$
\left\{\begin{array}{l}
X=V_{1} t \cos \alpha \\
Y=V_{1} t \sin \alpha+\frac{1}{2} g t^{2}
\end{array}\right.
$$

Appropriate horizontal distance and vertical distance from the seed-release point to the central point of driving pulley must be kept to make sure that seed enter seed delivery-cavity smoothly. If the vertical distance was too large, strong impact of seed drop would be generated and seed might rebound between the right seed-protecting board and the seed-delivery cavity, and seed might enter the next seed-delivery cavity mistakenly. This would result in skip and multiple sowing. On the other hand, the vertical distance can't be too short due to the limitation of the seed-delivery device's structure. The horizontal distance was determined as zero, and vertical distance was determined as $H_{1}\left(H_{1}=50 \mathrm{~mm}\right)$. The U-shaped electro-optical sensor was mounted at the angle of $\gamma$ $\left(\gamma=45^{\circ}\right)$ with the horizontal direction.

2.2.2 Analysis on balance time and determination of partition board spacing

The application of belt-type seed delivery device can not only reduce seed's release height and decrease seed's falling speed when seed is in contact with the furrow, but also decrease seed's bounce in furrow, thus improving seed spacing uniformity.

As the core part of belt-type seed delivery device, synchronous belt with partition board plays an important part in seed delivery process, and design parameters of seed delivery cavity directly affect the seed delivery. The synchronous belt with partition board consists of several equidistance seed delivery cavities. The distance of seed delivery cavity is one key design parameter.

Structure and kinematic parameters of belt-type seed delivery device are shown in Figure 3.

In order to ensure single-seed precision sowing, the number of seed delivery cavities that have passed U-shaped electro-optical sensor installation position should be integral multiple of the number of seeds that have released from the seed plate, and their quantitative relation can be presented as

$$
\frac{N n_{1} Z t}{60}=\frac{V_{2} t}{S}
$$

where, $N$ is positive integral; $n_{1}$ is the rotational speed of seed plate, $\mathrm{r} / \mathrm{min} ; n_{1}$ is the rotational speed of seed plate, $\mathrm{r} / \mathrm{min} ; Z$ is the number of holes in seed plate; $V_{2}$ is the seed's falling velocity from belt-type seed delivery device, $\mathrm{m} / \mathrm{s} ; S$ is the length of the seed delivery cavity, $\mathrm{m}$; $t$ is the seed's fall time from seed-release point, $\mathrm{s}$.

$V_{2}$ in Equation (4) can be expressed as:

$$
V_{2}=\frac{\pi n_{2} R_{2}}{30}
$$

where, $V_{2}$ is the seed's falling velocity from belt-type seed delivery device, $\mathrm{m} / \mathrm{s} ; n_{2}$ is the rotational speed of driving pulley, $\mathrm{r} / \mathrm{min} ; R_{2}$ is the outside radius of driving pulley, $\mathrm{m}$.

From Equations (4) and (5):

$$
N n_{1} Z=\frac{2 \pi n_{2} R_{2}}{S}
$$

where, $N$ is positive integral; $n_{1}$ is the rotational speed of seed plate, $\mathrm{r} / \mathrm{min} ; Z$ is the number of holes in seed plate; $n_{2}$ is the rotational speed of driving pulley, $\mathrm{r} / \mathrm{min} ; R_{2}$ is the outside radius of driving pulley, $\mathrm{m} ; S$ is the length of the seed delivery cavity, $\mathrm{m}$.

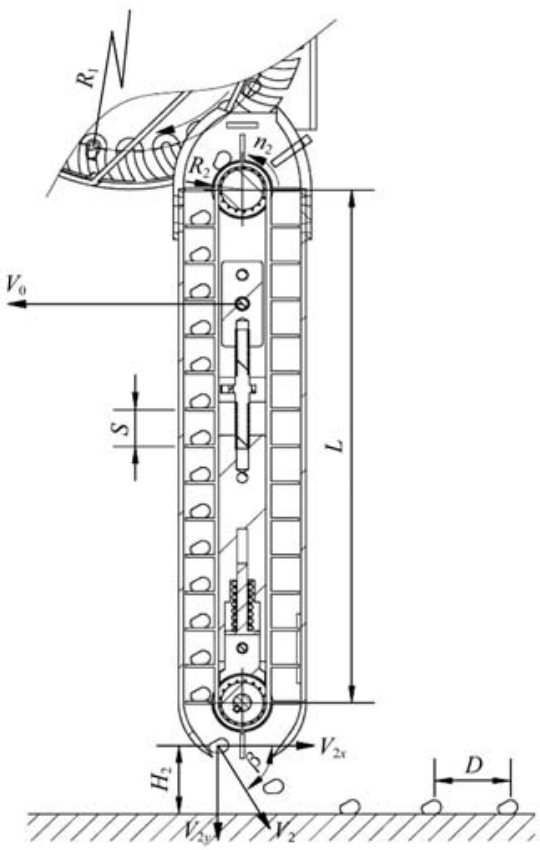

Note: $V_{0}$ is the forward speed of the maize planter $(\mathrm{km} / \mathrm{h}) ; n_{1}$ is the rotational speed of seed plate $(\mathrm{r} / \mathrm{min}) ; R_{1}$ is the distribution radius of seed hole in seed plate (m); $n_{2}$ is the rotational speed of driving pulley $(\mathrm{r} / \mathrm{min}) ; R_{2}$ is the outside radius of driving pulley $(\mathrm{m}) ; L$ is the center distance between driving pulley and driven pulley (m); $S$ is the length of the seed delivery device(m); $H_{2}$ is the distance in vertical direction between the bottom of the seed delivery device and the furrow $(\mathrm{m}) ; V_{2}$ is the seed's falling velocity from belt-type seed delivery device $(\mathrm{m} / \mathrm{s})$; $\beta$ is the angle between the seed slide and the horizontal direction $\left({ }^{\circ}\right) ; D$ is seed spacing in furrow $(\mathrm{m})$.

Figure 3 Parameters of seed precise delivery mechanism

Meanwhile, the number of seed delivery cavity that have passed U-shaped electro-optical sensor should be integral multiple of the number of seeds that have released from the seed delivery device at the same time period, it can be expressed as:

$$
\frac{5 N V_{0} t}{18 D}=\frac{V_{2} t}{S}
$$

where, $N$ is positive integral; $V_{0}$ is the forward speed of the maize planter, $\mathrm{km} / \mathrm{h} ; D$ is seed spacing in furrow, $\mathrm{m} ; V_{2}$ is the seed's falling velocity from belt-type seed delivery device, $\mathrm{m} / \mathrm{s} ; S$ is the length of the seed delivery cavity, $m$.

The forward speed of the maize planter $\left(V_{2}\right)$ can be expressed as:

$$
V_{0}=\frac{3 D n_{1} Z}{50}
$$

where, $V_{0}$ is the forward speed of maize planter, $\mathrm{km} / \mathrm{h} ; D$ is the seed spacing in furrow, $\mathrm{m} ; n_{1}$ is the rotational speed of seed plate, $\mathrm{r} / \mathrm{min} ; Z$ is the number of holes in seed plate.

Therefore, from Equations (6):

$$
S=\frac{2 \pi R_{2} n_{2}}{N Z n_{1}}
$$

where, $S$ is the length of the seed delivery cavity, $\mathrm{m} ; R_{2}$ is the outside radius of driving pulley, $\mathrm{m} ; n_{2}$ is the rotational speed of driving pulley, $\mathrm{r} / \mathrm{min} ; N$ is positive integral; $Z$ is the number of holes in seed plate; $n_{1}$ is the rotational speed of seed plate, $\mathrm{r} / \mathrm{min}$.

The seed delivery device was mounted between two disk diggers. Value of $R_{2}$ was determined as $16 \mathrm{~mm}$, and value of $L$ was $300 \mathrm{~mm}$ according to the distance between the bottom of seed meter and the furrow. Speed ratio of two step motors $i_{12}\left(i_{12}=\right.$ 
$n_{1} / n_{2}$ ) was determined as 6 , the number of holes was known as 25 .

Plugging the above parameters, Equation (9) is simplified into:

$$
S=\frac{24 \pi}{3125 N}
$$

If $N=1, S=24$, the synchronous belt with partition board was suitable for maize sowing. If $N=2, S=12$, sowing quality of the system became bad as the spacing between two adjacent partition board in synchronous belt was too small. If $N \geq 2$, sowing quality of the system became worse.

When the driving pulley rotated for $k$ laps, seed was delivered to the bottom of the seed delivery device, and it was expressed as:

$$
k=\frac{L}{2 \pi R_{2}}
$$

where, $k$ is the number of laps that the driving pulley has rotated; $L$ is the center distance between driving pulley and driven pulley, $\mathrm{m}$; $R_{2}$ is the outside radius of driving pulley, $\mathrm{m}$.

Plugging the known parameters to Equation (11), it was obtained that $k=3$.

2.2.3 Impact analysis of partition board on seed movement

When a seed passed the bottom of the seed delivery device, it fell into the furrow under the force of gravity, the seed's movement is shown in Figure 3. It is necessary to study whether partition board has an effect on the motion of the seed when it falls into the furrow from the bottom of the seed delivery device.

The time that one partition board takes to move for the length of one seed delivery cavity can be presented as:

$$
t=\frac{S}{V_{2}}
$$

where, $S$ is the length of the seed delivery cavity, $\mathrm{m} ; V_{2}$ is the seed's falling velocity from belt-type seed delivery device, $\mathrm{m} / \mathrm{s}$.

The distance in vertical direction from the bottom of the seed delivery device to the furrow can be presented as:

$$
H_{2}=V_{2} t \sin \beta+\frac{g t^{2}}{2}
$$

where, $\mathrm{H}_{2}$ is the distance in vertical direction between the bottom of the seed delivery device and the furrow, $\mathrm{m} ; V_{2}$ is the seed's falling velocity from belt-type seed delivery device, $\mathrm{m} / \mathrm{s} ; \beta$ is the angle between the seed slide and the horizontal direction, ${ }^{\circ}$.

From Equations (5), (12) and (13)

$$
H_{2}=S \sin \beta+\frac{450 S^{2} g}{\pi^{2} n_{2}^{2} R_{2}^{2}}
$$

where, $\mathrm{H}_{2}$ is the displacement of seed in vertical direction from seed release point in seed delivery device, $\mathrm{m} ; S$ is the length of the seed delivery cavity, $\mathrm{m} ; \beta$ is the angle between seed slide and horizontal direction, $\left({ }^{\circ}\right) ; n_{2}$ is the rotational speed of driving pulley, $\mathrm{r} / \mathrm{min} ; R_{2}$ is the outside radius of driving pulley, $\mathrm{m}$.

The maximum forward speed of maize planter $\left(V_{1}\right)$ as and the seed spacing in furrow $(D)$ were selected as $20 \mathrm{~km} / \mathrm{h}$ and $0.25 \mathrm{~m}$, respectively, the number of holes in seed plate $(Z)$ was known as 25 . Plugging the above parameters to Equation (8), it was obtained that $n_{1}=53.33 \mathrm{r} / \mathrm{min}$. It is known that $n_{1} / n_{2}=6$, so $n_{2}=320 \mathrm{r} / \mathrm{min}$. $\beta$ was determined as $55^{\circ}$, Plugging the above parameters to Equation (14), the value of $H_{2}$ was calculated as $29.5 \mathrm{~mm}$ which was considerably larger than the maximum length of maize seed. When the next partition board moved to the seed release point, the seed-falling height was $29.5 \mathrm{~mm}$, so the partition board wouldn't affect seed movement.

\subsection{Control system}

The control system was composed of forward speed sensor, controller, stepping servomotor, motor drive module, and human-machine interface. The electronic control diagram of seed precise delivery mechanism is shown in Figure 4. A controller detected the forward speed of the maize planter from the encoder mounted on the land wheel and processed the speed signal, then a PWM (pulse-width-modulation) signal was then generated by the controller in proportion to the forward speed input, and then it was sent to motor driver, and the signal was amplified and was used to drive the motor rotating at the desired speed. The encoder mounted on the motor was used to monitor the speed of motor and obtain a feedback, and the closed-loop control was used to improve rotary accuracy of the motor.

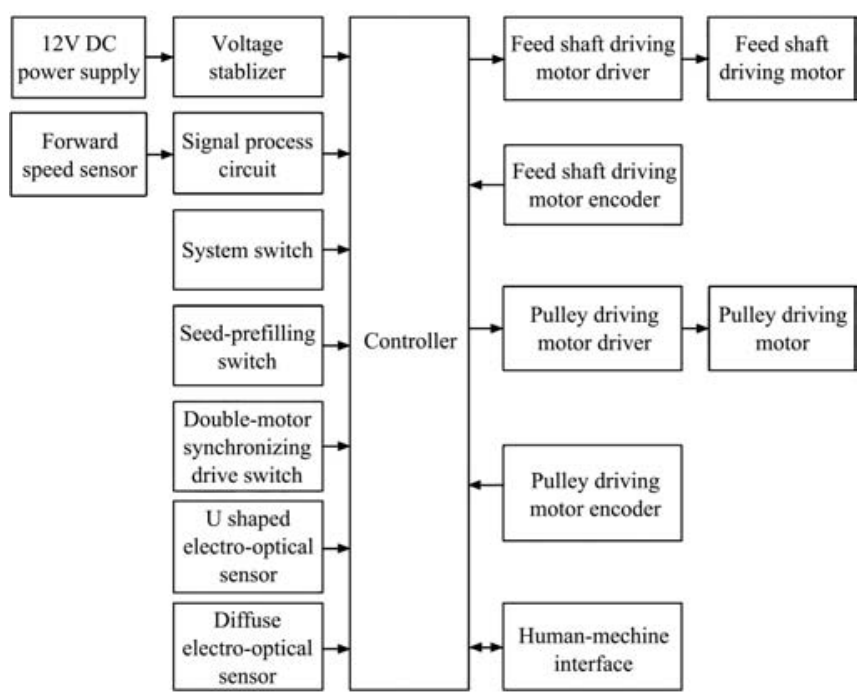

Figure 4 Block diagram of seed precise delivery mechanism

\subsubsection{Human-machine interface}

In order to realize human-machine interaction, RS485 inter-face is used, and a touch screen [Model MT4414T, Kinco, China] is chosen as the input and output unit of the system. Input parameter of the human-machine interface include the number of holes in the seed plate and the theoretical spacing, the output parameter include the forward speed of maize planter and motor speed.

\subsubsection{Maize planter's forward speed sensor}

When the maize planter is in operation, the speed of feed shaft driving motor must accurately match the forward speed of the maize planter, and the prerequisite is to accurately detect the forward speed of maize planter. The optical encoder had advantages of high accuracy, reliable work, and small size, so an optical encoder was chosen as the speed sensor of maize planter. The encoder is mounted beside the shaft of land wheel, and the encoder shaft is collinear with the shaft of the land wheel. The maximum response frequency of optical encoder $f_{\max }$ is represented as

$$
f_{\max }=\frac{c_{e} n_{\max }}{60}
$$

where, $f_{\max }$ is the maximum response frequency of optical encoder, $\mathrm{HZ} ; n_{\max }$ is the highest rotational speed of the land wheel, $\mathrm{r} / \mathrm{min} ; c_{\mathrm{e}}$ is the encoder resolution, $\mathrm{p} / \mathrm{r}$.

The highest rotational speed of the land wheel $n_{\max }$ is represented as:

$$
n_{\max }=\frac{60 V_{\max }}{7.2(1-\delta) \pi R_{4}}
$$

where, $V_{\max }$ is the highest forward speed of maize planter, $\mathrm{km} / \mathrm{h}$; $\delta$ is the land wheel slip ratio; R4 is the radius of the land wheel, $\mathrm{m}$. 
OMRON E6A2-CW3C encoder is chosen to detect the rotational speed of the land wheel, its resolution is $200 \mathrm{p} / \mathrm{r}$ (ce is $200 \mathrm{p} / \mathrm{r}$ ), the known parameter are listed as follows: $V_{\max }$ is determined as $20 \mathrm{~km} / \mathrm{h}, \delta$ is 10 percent and $\mathrm{R} 4$ is $0.35 \mathrm{~m}$. Plugging the above parameters to Equation (15), the value of $f_{\max }$ can be calculated as $f_{\max }=156 \mathrm{~Hz}$. The maximum response frequency of the selected encoder is $30 \mathrm{kHz}$, which meets the requirement of speed detection described in this study.

\subsubsection{Controller}

To achieve the target speed for the two motors as quickly as possible and maintain it, a PID controller was developed. Two PWM (pulse-width-modulation) pulses were generated by the controller in proportion to the forward speed of the maize planter, respectively. The frequency of PWM pulse that the controller sends to control seed meter rotation is represented as:

$$
f_{1}=\frac{N_{e}}{c_{e}} \cdot \frac{360}{\varphi} \cdot \frac{2 \pi R_{4}}{Z D}
$$

where, $f_{1}$ is the frequency of PWM pulse that the controller sends to control seed meter rotation, $\mathrm{p} / \mathrm{s} ; N_{\mathrm{e}}$ is the pulse frequency from the rotational speed of the land wheel, $\mathrm{p} / \mathrm{s} ; c_{\mathrm{e}}$ is the revolution of wheel rotational speed encoder, $\mathrm{p} / \mathrm{r} ; \psi$ is the step angle of feed shaft driving motor, $\left(^{\circ}\right) ; R_{4}$ is the radius of the land wheel, $\mathrm{m} ; Z$ is the number of holes in the seed plate; $D$ is the theoretical seed spacing, m.

The frequency of PWM pulse that the controller sends to control pulley driving motor is represented as:

$$
f_{2}=6 f_{1}
$$

where, $f_{2}$ is the frequency of PWM pulse that the controller sends to control pulley driving motor, $\mathrm{p} / \mathrm{s} ; f_{1}$ is the frequency of PWM pulse that the controller sends to control seed meter rotation, $\mathrm{p} / \mathrm{s}$.

\subsubsection{Driving motors}

Rated speed and rated torque are two key parameters in selecting a motor to be used for this study. Rotational speed of feed shaft driving motor for the seed meter is presented as:

$$
n_{1}=\frac{50 V_{0} i_{01}}{3 D Z}
$$

where, $n_{1}$ is the rotational speed of the seed meter, $\mathrm{r} / \mathrm{min} ; V_{0}$ is the forward speed of maize planter, $\mathrm{km} / \mathrm{h} ; i_{01}$ is the transmission ratio of the land wheel drive system, $D$ is the theoretical seed spacing, $\mathrm{m}$; $Z$ is the number of holes in seed plate.

Rotational speed of pulley driving motor for the belt is presented as:

$$
n_{2}=6 n_{1}
$$

The known parameters are as follows: $i_{01}=1, D=0.25 \mathrm{~m}$, and $Z=25$. Plugging the known parameters to Equations (19) and (20), the values of two parameters were obtained that $n_{1}=53.3 \mathrm{r} / \mathrm{min}$, $n_{2}=320 \mathrm{r} / \mathrm{min}$, respectively.

Friction torque is the main torque that acts on feed shaft when seed meter is in operation. The outside circle of feed shaft is held in the seal ring of air chamber with the action of negative pressure. Friction torque is generated when seed meter is in operation.

The friction torque is presented as:

$$
M_{f}=\mu \cdot|P| \cdot S \cdot L
$$

where, $M_{f}$ is the friction torque; $\mu$ is the friction coefficient between seed plate and seal ring; $P$ is the value of negative pressure in air chamber, $\mathrm{kPa}$; $S$ is the contact area between the air chamber and the seal ring, $\mathrm{m}^{2} ; L$ is the arm of friction, $\mathrm{m}$.

The known parameters are as follows: $\mu=0.4, P=-5 \mathrm{kPa}$, $S=0.0048 \mathrm{~m}^{2}$ and $L=0.07475 \mathrm{~m}$. Plugging the above parameters to Equation (21), the calculated value of $M_{f}$ is calculated as $0.72 \mathrm{~N} \cdot \mathrm{m}$.

The maximum torque that acts on pulley driving motor is measured by torque tester, and the measured value is $0.45 \mathrm{~N} \cdot \mathrm{m}$.

Based on the above calculations and analysis, the 57HB250-54B stepper servo DC motor was chosen as both the feed shaft driving motor for the seed meter, and the pulley driving motor for the belt. The rated speed of the motor is $1000 \mathrm{r} / \mathrm{min}$, and its rated torque is $1.5 \mathrm{~N} \cdot \mathrm{m}$, the two parameters both meet the system's working requirement in this study.

\subsection{Laboratory experiment}

To test the performance of seed precise delivery mechanism, the contrast experiment between the new developed mechanism and traditional seed tube delivery mechanism was conducted on the type JPS-12 computer vision-based seed meter performance test bench (Bona Science and Technology Ltd. Harbin, China). The test bench can be used to perform the experiment and test of the precision sowing, bunch sowing and drilling, and allowed real-time detection of sowing performance based on computer vision technology. The index of sowing performance of the precision seed meter, such as mean spacing, variation coefficient of seed spacing, quality of feed index, multiple index and miss index, can be determined by the seed meter test bench. The bench can also output experimental data and charts that meet the requirements of national standards. The input parameters, such as the rotation speed of the seed disc, positive pressure and forward speed of the conveyor belt, could be controlled during the seed meter test bench experiment. The seed precise delivery mechanism is mounted above the test bench using mounting bracket. The negative pressure that seed meter needs is provided by negative-pressure fan from the sticky belt test stand through the outlet of the seed meter. Sufficient oil was added to the top surface of the belt to capture the seed as it was released from the seed precise delivery mechanism to prevent rolling and bouncing on the belt surface (Figure 5).

A high-speed video camera (Phantom V 9.1, Vision Research Inc. USA) was used to record the movement of the seed in the seed delivery device. The camera is composed of three main components: the high-speed digital camera for recording of passing seed, the motion analyzer for image analysis, and the computer for data processing and monitoring. To obtain acceptable resolution of the seeds, a frame rate of $500 \mathrm{fps}$ was selected, and thus the time between consecutive images was $2 \mathrm{~ms}$. Image of $512 \times 384$ pixels was selected as the size of the picture. The camera was positioned at the transverse to the sticky belt and directly faced with the front case of seed delivery device.

Maize seed used in the experiment was Zhengdan 958 produced by Henan Academy of Agricultural Sciences. The seed was in yellow color, and in half horseshoe shape. The thousand seed-kernel weight was $330.4 \mathrm{~g}$, and the moisture content was $12.7 \%$. Experimental indexes included quality of feed index and coefficient of variation. Quality of feed index is calculated as:

$$
A=n_{1} / N^{\prime} \times 100 \%
$$

where, $A$ is quality of feed index, $\% ; n_{1}$ is the number of individual seed; is the sum of seeds falling from the seed precise delivery mechanism.

The theoretical seed spacing was set at $0.25 \mathrm{~m}$, and the negative pressure provided for seed meter was set at $-5 \mathrm{kPa}$, and the forward speeds of sticky belt were adjusted to $10 \mathrm{~km} / \mathrm{h}$, $12 \mathrm{~km} / \mathrm{h}$ and $14 \mathrm{~km} / \mathrm{h}$, respectively. The experiment was conducted with three replications, and the number of seed spacing was 250 each time. 


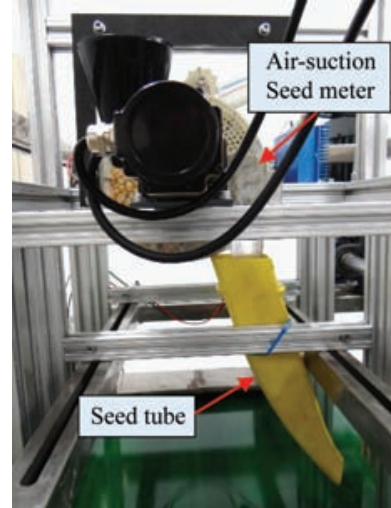

a. Traditional seed

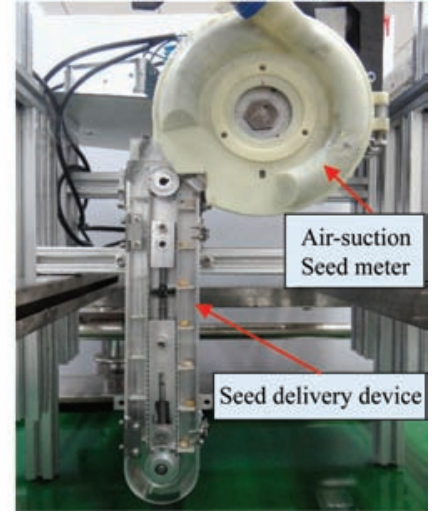

b. Seed precise delivery
Figure 5 Contrast experiment of the seed precise delivery mechanism and the traditional seed tube delivery system

\section{Results and discussion}

Seed spacing data of seed precise delivery mechanism and the traditional seed tube delivery mechanism is shown in Table 1 , and the mean values of quality of feed index at three different forward speeds are shown in Figure 6, and the mean values of coefficient of variation are shown in Figure 7.

The data was analyzed using the IBM SPSS statistics software package. The "Paired-Samples T Test" command included in "Compare Means" was used to perform the analysis of variance, which was appropriate for a randomized complete block design. Statistical significance was evaluated at the $p<0.05$ level. Output results are as follows: the significance level of quality of seed index was 0.311 , and the significance level of coefficient of variation was 0.002 .

Table 1 Seed spacing data of seed precise delivery mechanism and the traditional seed tube delivery mechanism

\begin{tabular}{|c|c|c|c|c|c|}
\hline \multirow[b]{2}{*}{$\begin{array}{l}\text { Travel } \\
\text { speed } \\
/ \mathrm{km} \cdot \mathrm{h}^{-1}\end{array}$} & \multirow[b]{2}{*}{$\begin{array}{c}\text { Sequence } \\
\text { number }\end{array}$} & \multicolumn{2}{|c|}{ Quality of feed index $/ \%$} & \multicolumn{2}{|c|}{ Coefficient of variation $/ \%$} \\
\hline & & $\begin{array}{l}\text { Traditional seed } \\
\text { tube delivery } \\
\text { system }\end{array}$ & $\begin{array}{l}\text { Belt-type } \\
\text { seed delivery } \\
\text { system }\end{array}$ & $\begin{array}{l}\text { Traditional seed } \\
\text { tube delivery } \\
\text { system }\end{array}$ & $\begin{array}{l}\text { Belt-type } \\
\text { seed delivery } \\
\text { system }\end{array}$ \\
\hline \multirow{3}{*}{10} & 1 & 91.20 & 92.80 & 18.60 & 8.14 \\
\hline & 2 & 90.46 & 90.47 & 20.61 & 10.28 \\
\hline & 3 & 89.06 & 90.47 & 18.48 & 14.85 \\
\hline \multirow{3}{*}{12} & 1 & 79.51 & 84.34 & 20.52 & 18.03 \\
\hline & 2 & 88.21 & 89.84 & 20.77 & 20.41 \\
\hline & 3 & 84.17 & 79.45 & 24.85 & 17.39 \\
\hline \multirow{3}{*}{14} & 1 & 74.40 & 79.22 & 23.31 & 22.64 \\
\hline & 2 & 74.71 & 81.38 & 22.76 & 21.83 \\
\hline & 3 & 76.68 & 72.87 & 24.07 & 23.74 \\
\hline
\end{tabular}

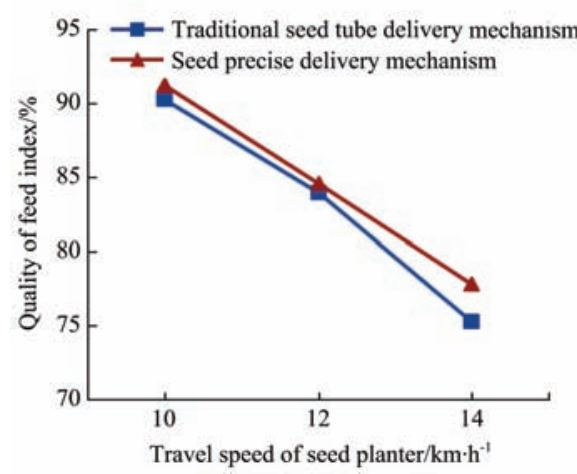

Figure 6 Line chart of quality of feed index from seed precise delivery mechanism and traditional seed tube delivery mechanism

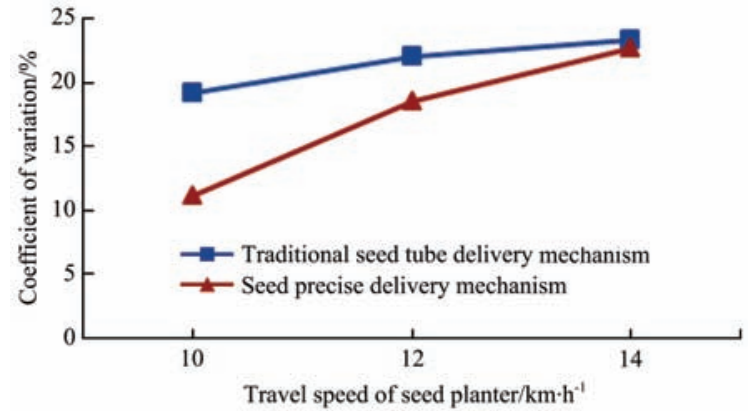

Figure 7 Line chart of coefficient of variation of seed precise delivery mechanism and traditional seed tube delivery mechanism at three different forward speeds

As Figure 6 shows, the increase of the forward speed from $10 \mathrm{~km} / \mathrm{h}$ to $14 \mathrm{~km} / \mathrm{h}$ resulted in a decrease from $90.24 \%$ to $75.26 \%$ in the quality of feed index from traditional seed tube delivery system, and the qualities of feed index from the seed precise delivery mechanism are higher than the traditional seed tube mechanism at three different forward speeds. It indicated that the seed precise delivery mechanism improved the quality of feed index compared with the traditional seed tube mechanism. Figure 7 shows that the coefficient of variation also varies with the forward speed of maize planter. The coefficient of variation of the seed tube delivery mechanism increased from $19.23 \%$ to $23.38 \%$, and the coefficients of variation of seed precise delivery mechanism are lower than the traditional seed tube mechanism at three different forward speeds. Based on above analysis, the conclusion is drawn that the seed precise delivery mechanism improved seed spacing uniformity compared with the traditional seed tube mechanism.

The quality of feed index and the coefficient of variation from seed precise delivery mechanism was $75.26 \%$ and $22.74 \%$ at the forward speed of $14 \mathrm{~km} / \mathrm{h}$, which indicated that the seed uniformity became worse at the forward speed of $14 \mathrm{~km} / \mathrm{h}$. In order to explore the reasons for it, high-speed video was analyzed when the seed precise delivery mechanism worked at the forward speed of $14 \mathrm{~km} / \mathrm{h}$.

Figure 8 shows the release positions of two consecutive seeds in seed delivery cavity. It was observed that release positons of two consecutive seeds varied dramatically in the horizontal direction, which resulted in a great error of horizontal displacement, the error led to the result that the seed entered a seed delivery cavity which it should not enter, and then miss-sowing and double-sowing occurred.

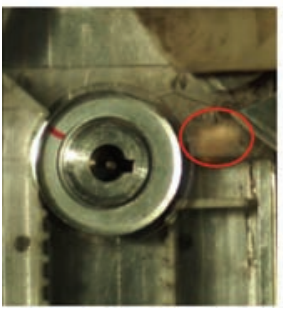

a

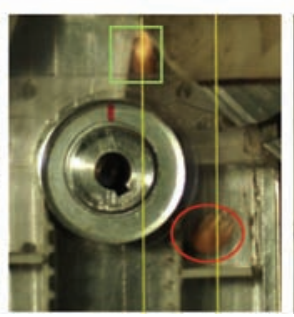

b

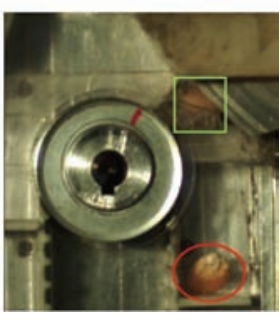

Figure 8 Release positions of two consecutive seeds in seed delivery mechanism

Figure 9 shows tracking of one seed in the seed delivery device by the time. The seed was in contact with partition board and moved to the right seed-protecting board with the action of push force from the partition board, and the seed moved to the adjacent seed delivery cavity with the reaction force of the right 
seed-protecting board, which resulted in miss-seeding and reseeding.

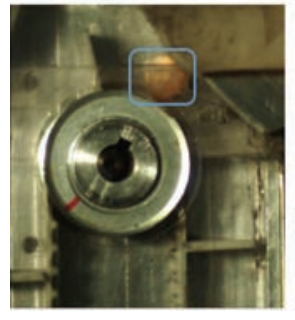

a

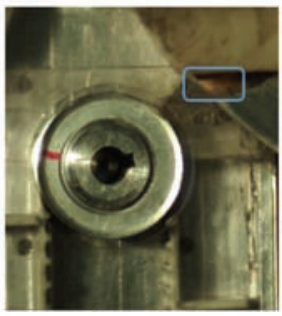

b

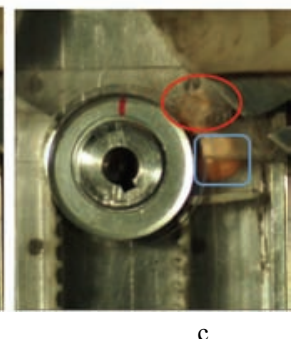

Figure 9 Tracking of a seed in the seed delivery mechanism by the time

Figure 10 shows movements of two seeds on slide at the bottom of seed delivery mechanism. It can be seen from the two paragraphs in Figure 10 a that the seed was separated from partition board and was contact with the top of the slide, along which the seed slid down. The two photographs in Figure $10 \mathrm{~b}$ showed that another seed was separated from partition board and was contact with the middle of the slide and bounced. The above-mentioned facts resulted in an increase in coefficient of variation with the increase of the forward speed of maize planter.
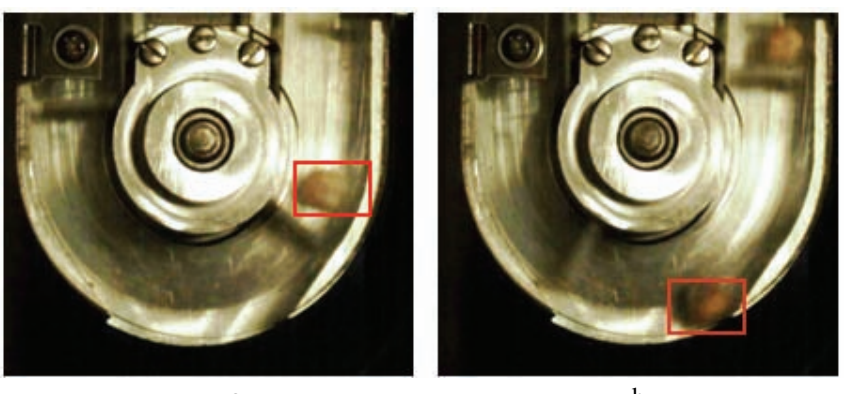

Figure 10 Movements of two seeds on slide at the bottom of the seed delivery mechanism

\section{Conclusions}

This study designed the seed precise delivery mechanism. Kinematic analysis of seed has been conducted from the seed release point in the seed meter to the seed delivery cavity, and the mathematical model of seed's movement has been established from the seed release point to the furrow with the belt-type seed delivery device. Key components of control unit have been chosen and designed based on the requirement of the mechanism. Performance experiment of the seed precise delivery mechanism has been conducted in a bench testing in the lab, and seed's movement in the mechanism has been analyzed using high-speed camera. The analytic results have shown as follows: the seed precise delivery mechanism improved the quality of feed index compared with the traditional seed tube mechanism, and decreased the coefficient of variation at three different forward speeds of the maize planter. Based on above analysis, the conclusion is drawn that the seed precise delivery mechanism improved seed spacing uniformity compared with the traditional seed tube mechanism.

\section{Acknowledgements}

The authors disclosed receipt of the following financial support for the research, authorship, and/or publication of this article: This work was funded by the National Natural Science Foundation of
China (Grant No.51575515), the National key research and development program in 13th Five-Year (Grant No.2017YFD0700703), the Soil-Machine-Plant Key Laboratory of the Ministry of Agriculture of PR China and Project of the Modern National Industry System of Maize Industrial Technology (CARS-02).

\section{[References]}

[1] Singh R C, Singh G, Saraswat D C. Optimization of design and operational parameters of a pneumatic seed metering device for planting cottonseeds. Biosystems Engineering, 2005; 92: 429-438.

[2] Allen R R, Hollingsworth L D, Thomas J D. Sunflower planting and emergence with coated seed. Trans of the ASAE, 1983; 26: 665-668.

[3] Halderson J L. Planter selection accuracy for edible beans. Trans of the ASAE 1983; 26: 367-371.

[4] Ozmerzi A. Seed distribution performance of the furrow openers used on drill machines. AMA Agric Mech Asia Afr Lat Am, 1986; 17: 32-34.

[5] Panning J W. Seed spacing performance for general purpose and specialty type sugar beet planters. MS Thesis, USA: University of Nebraska, 1997.

[6] Jasa P J, Dickey E C. Tillage factors affecting corn seed spacing. Trans. ASAE, 1982; 25(6): 1516-1519.

[7] Liu J, Cui T, Zhang D X, Yang L, Shi Song. Mechanical-pneumatic Combined Corn Precision Seed-metering device. Transactions of CSAM, 2012; 43(2): 43-47. (in Chinese)

[8] Karayel D, Ozmerzi A. Effect of tillage methods on sowing uniformity of maize. Can Biosyst Eng, 2002; 44: 2.23-2.26.

[9] Shi S, Zhang D X, Yang L, Cui T, Zhang R, Yin X W. Design and experiment of pneumatic maize precision seed meter with combined holes. Transactions of CSAE, 2014; 30(5): 10-18. (in Chinese)

[10] Brooks D, Church B. Drill performance assessments: changed approach. Br Sugar Beet Rev, 1987; 50: 13-15.

[11] Kachman S D, Smith, J A. Alternative measures of accuracy in plant spacing for planters using single seed metering. Trans of the ASAE, 1995; 38(2): 379-387

[12] Ozmerzi A, Karayel D. The effect of the tooth harrow covers of the grain seeders on seed distribution in soil. J. Univ. Akdeniz, Faculty Agricult, 1999; 11: 75-79.

[13] Parish R L, Bracy R P. Metering non-uniform vegetable seed. Hort Tech, 1998; 8: 69-71.

[14] Karayel D, Wiesehoff M, Ozmerzi A. Laboratory measurement of seed drill seed spacing and velocity of fall of seeds using high-speed camera system. Comput Electron Agr, 2006; 50: 89-96.

[15] Ozmerzi A, Karayel D, Topakci M. Effect of sowing depth on precision seeder uniformity. Biosyst Eng, 2002; 82: 227-230.

[16] Erbach D C, Wilkins D E, Lovely W G. Relationships between furrow opener, maize plant spacing, and yield. Agron J, 1972; 64: 702-704.

[17] Moody F H, Hancock J H, Wilkerson J B. Evaluating planter performance-cotton seed placement accuracy. ASAE Paper No. 031146, 2003; St Joseph, Michigan, USA: ASAE.

[18] Ju X Q. Seed tube analysis of DOHN DEERE 7000 type precision seeder. Transactions of the CSAM 1981; 78-82. (in Chinese)

[19] Liu L J, Yang H. 3D reverse engineering design on seed tube based on Geomagic Design software. Transactions of the CSAE, 2015; 31(11): 40-45. (in Chinese)

[20] Gao R. The study of microcomputer design method on the seed tube of precision plant. Transactions of the CSAE, 1990; 6(4): 60-66. (in Chinese)

[21] He J L, Yang T, Qiu Z R. Design and research of the curve of seed tube in 2BQYF-6A direct seeder. J Shanxi Agric Univ, 2000; 20: 389-391. (in Chinese)

[22] Che J Z, Yu L, Li Q Y. Design and study on the double-disk no-till planter for wheat. Journal of Shandong University of Technology: Natural Science Edition, 2011; 25: 25-28. (in Chinese)

[23] McGrego K C, Mutcher C K. Soil loss from conservation tillage for sorghum. Transactions of the ASAE 1992; 35: 1841-1845.

[24] Zhang X R, He J, Li H W, Li W Y. Design and experiment on the driving disc of anti-blocking unit for no-tillage planter. Transactions of the CSAE 2009; 25(9): 117-121. (in Chinese) 